\title{
Working paper: An exploratory survey on the perceived risk of COVID-19 and travelling
}

\author{
Peraphan Jittrapirom* \\ Global Carbon Project \\ National Institute for Environmental Studies, \\ Tsukuba, Japan \\ Tel: +81-29-850-2545 \\ jittrapirom.peraphan@nies.go.jp
}
Garavig Tanaksaranond
Faculty of Engineering,
Chulalongkorn University,
Bangkok, Thailand
Tel +66822186653 ext 31
garavig.t@chula.ac.th

\begin{abstract}
-.
In the face of an emerging and novel pandemic, perceptions of its danger and probability of being affected can influence how an individual take precautionary actions. We performed an exploratory study to examine how travellers perceive the risk-related to COVID-19 and how the outbreak has affected their commuting and non-commuting travel activities. Building on previous studies, we propose a working hypothesis of personal risk perception and trip adjustment decision and collect information to preliminary check our hypothesis. We report on our work, and the results of an online survey carried out between March 12-19, 2020, which collected 71 responds from countries in Europe, Asia, Australia, and the Middle East in this working paper.

Our results illustrate how the respondents altered their travel, their rationales, the precautionary actions they took, their foremost concerns, the sources of information they based their decisions on, and how useful they found teleconference as an alternative. Also, we observed their risk-related perception concerning the proposed model. We found several potential correlations and some regional and country variations but were unable to draw any definitive conclusion due to the limited sample size. We share our preliminary results here for discussion purposes.
\end{abstract}

The research team would like to express our condolences to those who are affected by the outbreak caused by the novel coronavirus.

\section{BACKGROUND}

Since its emergence in late 2019, the novel Coronavirus or COVID-19 has rapidly spread beyond nations' borders and caused significant impacts to the livelihoods of people around the world. As of $1^{\text {st }}$ April, nearly 800,000 pandemic cases have been observed in 203 counties, areas, and territories, and resulted in 40,000 mortalities (WHO, 2020). The associated socio-economic impacts of this event have also been far-reaching as en-mass losses of employment is continued, heightening the potential large-scale collapse of global economics.

The spread of this pandemic disease and their intensified impacts have also caused, the lock-down of several cities by the authorities and the cancellation of flights and other transport services. Individuals have voluntarily adjusted their commuting and travelling to avoid being infected. Several others are following the advice of their employers or governments or inevitably affected by the postponement of their appointment or the enforced measures to promote social distancing. It is estimated that approximately $20-30 \%$ of the world population is under restricted movements due to the outbreak (Business Insider, 2020) - See Appendix for worldwide lockdown timeline. However, it is uncertain how and in what way are people adjusting their travel and commuting under the current situation. 


\section{AIM AND OBJECTIVES}

In this exploratory study, we examine how the COVID-19 outbreak and the associated responding measures to contain the infectious disease affect the movements of people and their travel-related decisions. The focus of this study is to elucidate 1) how travellers are affected by the arising pandemic threats, 2) what are the perceived factors that determine their decisions to travel or not, and 3) how sociodemographic attributes, such as country of residence, affect the perceived factors.

Our study builds on the findings of Sadique et al. (2007), which examined the precautionary actions taken to reduce risk in the face of SARS epidemics. We use this preliminary study to expand on the perceived factors that may affect the decision to travel or not beyond the traditional definition of risk that is based on the protection motivation theory (i.e. likelihood and severity). We include the perceived certainty of information and impact directness as factors that can influence perceived personal risk. Also, we seek to clarify how sociodemographic attributes, such as gender, country or region of residents, prior experience with wide-scale transport disruption and personal opinion may influence how risk is perceived by the individual. Our working hypothesis model is depicted in Figure 1.

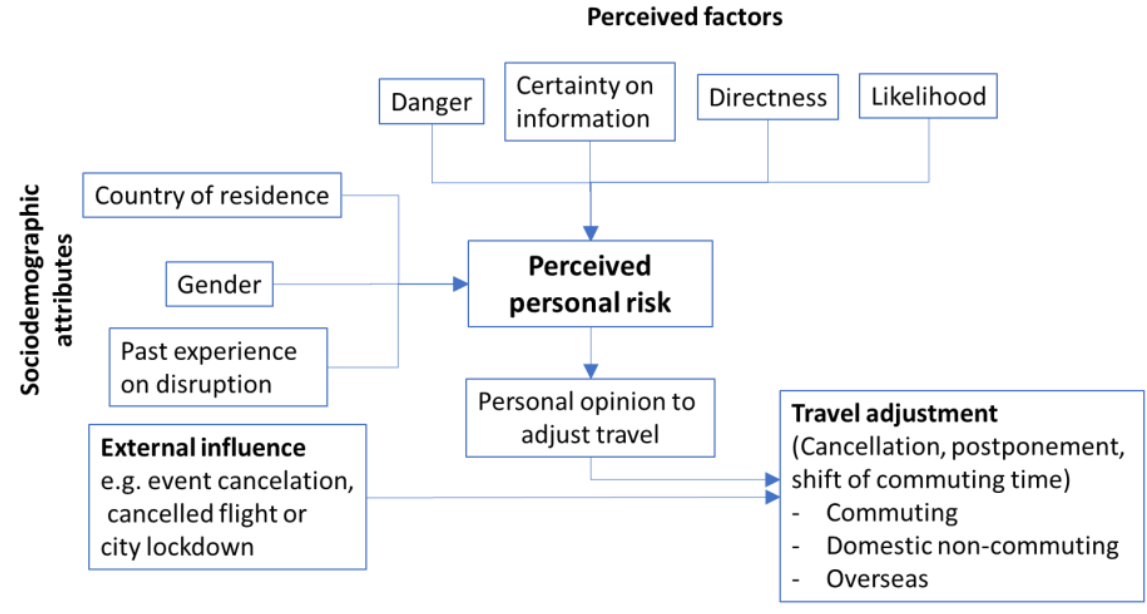

Figure 1 Working hypothesized model

The scope of the survey is intentionally broad. It addresses both the commuting and non-commuting trips and overseas and domestic travels. We report the early outcomes here to facilitate the discussion on the topics and to provide inputs for other on-going related studies.

There are some report and on-going surveys that examine the impacts of the COVID-19 outbreaks on travelling, despite its recent advent. A study by the Global Web Index, a market research company, examined the effects of COVID-19 to the US and UK's tourism and transport industry from a consumer perspective (GWI, 2020). The survey was carried out between March 13-16, 2020 and collected more than 1,500 samples from each country. The GWI survey dealt explicitly with the perception of the outbreak and its impacts on vocational travel and daily commuting. The on-going efforts by Research Center of Transport Planning and Traffic Engineering, (Vienna University of Technology, Austria) ${ }^{1}$, Technical University Dresden ${ }^{2}$, the Transport research group at Southampton University $^{3}$, and Institute of Transport and Logistics Studies, University of Sydney are also addressing different aspects of the issues. The first two surveys are examining the impacts of COVID-19 on daily mobility behaviour, while Southampton's study also focuses on logistics and delivery. In addition to these studies, Google has provided a report on COVID-19 Community Mobility ${ }^{4}$, which presents sets of aggregated and anonymised data to illustrate the changes in mobility relative to the pre-COVID-19 baseline.

In addition, lessons can be drawn from studies that examined the impacts on travellers by pandemic diseases, such as severe acute respiratory syndrome (SARS) and Middle East respiratory syndrome coronavirus (MERS-CoV). (e.g. Pavli, Tsiodras, \& Maltezou, 2014; Wilder-Smith, 2006). However, it is essential to note that applications of the lessons learnt from these past events would need to consider how COVID-19 and its associated impacts are different from the previous outbreaks. For instance, how COVID-19 has a longer incubation period, a

\footnotetext{
${ }^{1}$ https://blog.fvv.tuwien.ac.at/corona/?fbclid=IwAR3RtXoavEATV18 7sk28Sq0Bt6jkn4Rskx 5Ecyx8FZqhcOvb6Mgz8wVys

${ }^{2}$ https://umfragen.psych.tu-dresden.de/sozsci/coronamobility/

3 https://www.isurvey.soton.ac.uk/36433

${ }^{4}$ https://www.google.com/covid19/mobility/
} 
large proportion of asymptomatic transmission, which results in a more rapid and expansive in its spread (Peeri, Bibi, \& Baghbanzadeh, 2020).

\section{METHODOLOGY}

We carried out an international online survey between March 12-19, 2020, using an online survey platform. Initially, we planned for a longer survey period but decided to halt the collection as at the time the affected population was increasing due to the outbreaks in Europe and the USA. The rapid escalating of the situation resulted in several international travel restrictions and domestic 'lockdowns' being placed on countries, such as the US, UK, and several European countries overnight (See Appendix A). These changes meant that results collected in the previous week by respondents from the same country might yield completely different results. Moreover, the survey team would like to minimize any disruptions to those who may be affected by the events.

For these reasons, the survey period was concise. We distributed the survey via email, social media, and professional networks. During the seven days, we collected 138 samples, of which 71 were completed (51\%). We omitted the incomplete samples from the analysis, which were carried out using the SPSS package version 22.

\section{RESUlts}

\section{A. Descriptive analysis}

We grouped the samples into two sets by the respondents' residential region; 1) Europe and 2) Asia, Australia, and the Middle East. We did not receive any response from the other areas (e.g. Africa or North and South America). The sociodemographic backgrounds of the respondents are shown in Table 1. In total, we collected 71 samples, of which 51 (71\%) are from European countries (Italy, the Netherlands, Germany, Austria, Belgium, Hungary, Lithuania, Malta, Norway, Portugal, and Spain). The rest $(\mathrm{n}=20)$ are from Asia (Japan, Thailand, China, and Singapore), the Middle East (Iran and Turkey), and Australia. We refer to this group in this report as the non-European.

Most of the respondents are females (61\%) and those who are full-time workers (73\%). The average age of the respondents is 37.9 ( $\mathrm{SD}=10.4$ ) years old. A high proportion works in research or academic positions $(48 \%)$ and has at least a master's degree (55\%). Nearly all of them (87\%) have not experienced any large-scale event that disrupts travelling and commuting. Examples of such events are SARS outbreak, volcano eruptions, 2009 Swine flu, the 2011 Great East Japan Earthquake, and traffic management due to a state-person visit.

Table 1 Sociodemographic information

\begin{tabular}{|c|c|c|c|}
\hline & $\begin{array}{c}\text { All } \\
(n=71)\end{array}$ & $\begin{array}{l}\text { Europe } \\
(n=51)\end{array}$ & $\begin{array}{l}\text { Asia, Australia, M East } \\
(\mathrm{n}=\mathbf{2 0})\end{array}$ \\
\hline \multicolumn{4}{|l|}{ Sex: } \\
\hline Male : Female & $28: 43(39 \%: 61 \%)$ & $20: 31(39 \%: 61 \%)$ & $8: 12(40 \%: 60 \%)$ \\
\hline \multicolumn{4}{|l|}{ Employment: } \\
\hline Working full-time (> 32hr per week) & $52(73 \%)$ & $35(69 \%)$ & $17(85 \%)$ \\
\hline Working part-time ( $<32 \mathrm{hr}$ per week) & $8(11 \%)$ & $6(12 \%)$ & $2(10 \%)$ \\
\hline Students & $7(10 \%)$ & $6(12 \%)$ & $1(5 \%)$ \\
\hline Retired & $1(1 \%)$ & $1(2 \%)$ & $0(0 \%)$ \\
\hline Not working (other) & $2(3 \%)$ & $2(4 \%)$ & $0(0 \%)$ \\
\hline Prefer not to answer & $1(1 \%)$ & $1(2 \%)$ & $0(0 \%)$ \\
\hline Free-lancing & $0(0 \%)$ & $0(0 \%)$ & $0(0 \%)$ \\
\hline \multicolumn{4}{|l|}{ Occupation: } \\
\hline Academic and research & $34(48 \%)$ & $24(47 \%)$ & $10(50 \%)$ \\
\hline Construction, extraction, and maintenance & $1(1 \%)$ & $1(2 \%)$ & $0(0 \%)$ \\
\hline Farming, fishing, and forestry & $0(0 \%)$ & $0(0 \%)$ & $0(0 \%)$ \\
\hline Government & $11(15 \%)$ & $6(12 \%)$ & $5(25 \%)$ \\
\hline Management, professional, and related & $9(13 \%)$ & $7(14 \%)$ & $2(10 \%)$ \\
\hline $\begin{array}{l}\text { Production, transportation, and material } \\
\text { moving }\end{array}$ & $0(0 \%)$ & $0(0 \%)$ & $0(0 \%)$ \\
\hline Service & $5(7 \%)$ & $5(10 \%)$ & $0(0 \%)$ \\
\hline Sales and office & $1(1 \%)$ & $0(0 \%)$ & $1(5 \%)$ \\
\hline Other, please specify & $10(14 \%)$ & $8(16 \%)$ & $2(10 \%)$ \\
\hline \multicolumn{4}{|l|}{ Highest level of education: } \\
\hline Less than high school degree & $1(1 \%)$ & $1(2 \%)$ & $0(0 \%)$ \\
\hline High school graduate or equivalent & $5(7 \%)$ & $5(10 \%)$ & $0(0 \%)$ \\
\hline Bachelor's degree or equivalent & $9(13 \%)$ & $7(14 \%)$ & $2(10 \%)$ \\
\hline Master's degree & $39(55 \%)$ & $31(61 \%)$ & $8(40 \%)$ \\
\hline Doctoral degree & $17(24 \%)$ & $7(14 \%)$ & $10(50 \%)$ \\
\hline \multicolumn{4}{|c|}{ Experience with large scale transport disruption: } \\
\hline Yes & $9(13 \%)$ & $5(10 \%)$ & $4(20 \%)$ \\
\hline
\end{tabular}


In Table 2, we report the disrupted and induced trips of the respondents. For commuting trips, a majority of the respondents $(39 \%)$ worked or studied from home every day, and nearly one-third worked/studied from home some days of the week, $15 \%$ shifted their commuting time, and $30 \%$ were not affected. There is a higher percentage of respondents working from home among the European (72\%) than those from Asia, Australia and the Middle East $(50 \%)$. Fifty per cent of those from the latter regions shifted their commuting time. Given the distributive percentages of occupations of the two groups are similar, the differences suggest that the employment conditions in Europe are better in facilitating working-from-home. On the other hand, those in other regions may shift their working time to avoid travelling during the peak periods.

For non-commuting domestic trips, $63 \%$ of the respondents cancelled or postponed their trips, $18 \%$ were still pending decision, and $21 \%$ were not affected. There are slight but not significant variations across the regions. For non-commuting overseas trips, $68 \%$ of the respondents cancelled or postponed their trips, $10 \%$ were still pending decision, and $25 \%$ were not affected. The variations across regions are more significant; a lower proportion of European respondents cancelled their overseas trip (10\% lower), which may suggest a more lenient regulation in this area at the time.

Table 2 Disrupted and induced trips

\begin{tabular}{lrrr}
\hline Type of trips disrupted or induced & $\begin{array}{c}\text { All } \\
(\mathbf{n = 7 1})\end{array}$ & $\begin{array}{c}\text { Europe } \\
(\mathbf{n = 5 1})\end{array}$ & $\begin{array}{c}\text { Asia, Australia, M East } \\
(\mathbf{n}=\mathbf{2 0})\end{array}$ \\
\hline Commuting trips* & & & \\
$\quad$ Work/study from home everyday & $28(39 \%)$ & $24(47 \%)$ & $4(20 \%)$ \\
$\quad$ Work/study from home some days & $19(27 \%)$ & $13(25 \%)$ & $6(30 \%)$ \\
$\quad$ Shifted commuting time & $11(15 \%)$ & $6(12 \%)$ & $5(25 \%)$ \\
$\quad$ No effects & $21(30 \%)$ & $13(25 \%)$ & $8(40 \%)$ \\
Non-commuting domestic trips* & & & \\
$\quad$ Cancelled or postponed & $45(63 \%)$ & $32(63 \%)$ & $13(65 \%)$ \\
$\quad$ Considering cancelling or postponing & $13(18 \%)$ & $10(20 \%)$ & $3(15 \%)$ \\
$\quad$ No effects & $15(21 \%)$ & $10(20 \%)$ & $5(25 \%)$ \\
Non-commuting overseas trips* & & & \\
$\quad$ Cancelled or postponed & $48(68 \%)$ & $33(65 \%)$ & $15(75 \%)$ \\
$\quad$ Considering cancelling or postponing & $7(10 \%)$ & $5(10 \%)$ & $2(10 \%)$ \\
$\quad$ No effects & $18(25 \%)$ & $14(27 \%)$ & $4(20 \%)$ \\
Induced non-commuting trips* & & & $5(25 \%)$ \\
$\quad$ Induced domestic trips & $17(24 \%)$ & $12(24 \%)$ & $8(40 \%)$ \\
$\quad$ Induced overseas trips & $21(30 \%)$ & $13(25 \%)$ & $11(55 \%)$ \\
$\quad$ No effects & $44(62 \%)$ & $33(65 \%)$ &
\end{tabular}

Note: $*$ - multiple selections allowed

The outbreak of COVID-19 also induced non-commuting trips for some respondents; $24 \%$ of the respondents had to make additional domestic travels and 30\% internationally. However, a majority (62\%) of the respondents were not affected. A higher proportion of non-European respondents saw induced overseas trips than the European respondents (40\% compared to $25 \%$ ). Some of the reasons for these induced trips are individual visits to smaller groups in place of a large class, visiting family, additional project meetings, responding meetings to the outbreak, and health-related checkups.

Among respondents who shifted their commuting trip, most of them (63\%) either depart 30 minutes earlier or later than the usual time. Most of them also decided to change their commuting time by themselves (73\%). There are insignificant differences between the two groups. In the European group, this proportion is slightly higher (83\%, compared with 60\%). In the non-European group, governmental advice is also considered.

Table 3 Commuting trips

\begin{tabular}{|c|c|c|c|}
\hline Affected Commuting trips & $\underset{\substack{\text { All } \\
(\mathbf{n}=\mathbf{1 1})}}{ }$ & $\begin{array}{c}\text { Europe } \\
(n=6)\end{array}$ & $\begin{array}{l}\text { Asia, Australia, M East } \\
(n=5)\end{array}$ \\
\hline \multicolumn{4}{|c|}{ How do you shift from the usual time? } \\
\hline Earlier - less than $30 \mathrm{~min}$ & $3(27 \%)$ & $2(33 \%)$ & $1(20 \%)$ \\
\hline Earlier - $30 \mathrm{~min}-1 \mathrm{hr}$ & $1(9 \%)$ & $1(17 \%)$ & $0(0 \%)$ \\
\hline Earlier - more than $1 \mathrm{hr}$ & $0(0 \%)$ & $0(0 \%)$ & $0(0 \%)$ \\
\hline Later - less than $30 \mathrm{~min}$ & $4(36 \%)$ & $2(33 \%)$ & $2(40 \%)$ \\
\hline Later - $30 \mathrm{~min}-1 \mathrm{hr}$ & $1(9 \%)$ & $0(0 \%)$ & $1(20 \%)$ \\
\hline Later - more than $1 \mathrm{hr}$ & $2(18 \%)$ & $1(17 \%)$ & $1(20 \%)$ \\
\hline \multicolumn{4}{|c|}{ Why do you shift your commuting time? } \\
\hline My employer asks me to & $0(0 \%)$ & $0(0 \%)$ & $0(0 \%)$ \\
\hline The government advise me to & $1(9 \%)$ & $0(0 \%)$ & $1(20 \%)$ \\
\hline I personally decided & $8(73 \%)$ & $5(83 \%)$ & $3(60 \%)$ \\
\hline Other, please specify & $2(18 \%)$ & $1(17 \%)$ & $1(20 \%)$ \\
\hline
\end{tabular}

For overseas and domestic non-commuting trips, about the same proportion of the total respondents cancelled or postponed their trips because of their decisions and the decisions of the events' organisers (45\%). Slightly more than one in three $(35 \%)$ decided based on government restrictions, and one in five $(21 \%)$ are affected by the transport providers' decision (e.g. flight or train cancellation). A higher proportion of European peers are affected by the event organisers (49\%, compared with 35\%) and the government (39\%, compared with $25 \%$ ) than its 
counterpart. Additionally, the respondents from non-European countries took more autonomy in cancelling or postponing these trips (60\%, compared with $39 \%)$.

Most of the respondents ( $80 \%$ ) have affected trips within the next three months. Most of the non-Europeans respondents $(50 \%)$ altered their trip one month ahead, whereas the European peers have more distributed affected periods (between one week to three months).

Table 4 Non-commuting trips

\begin{tabular}{|c|c|c|c|}
\hline Affected non-commuting trips & $\begin{array}{c}\text { All } \\
(n=71)\end{array}$ & $\begin{array}{l}\text { Europe } \\
(n=51)\end{array}$ & $\begin{array}{c}\text { Asia, Australia, M East } \\
(n=20)\end{array}$ \\
\hline \multicolumn{4}{|l|}{ What were the primary reasons for these affected trips?* } \\
\hline Decisions of the organizers & $32(45 \%)$ & $25(49 \%)$ & $7(35 \%)$ \\
\hline Decision of the government e.g. restricted border & $25(35 \%)$ & $20(39 \%)$ & $5(25 \%)$ \\
\hline Decision of my employer & $9(13 \%)$ & $5(10 \%)$ & $4(20 \%)$ \\
\hline My personal decision & $32(45 \%)$ & $20(39 \%)$ & $12(60 \%)$ \\
\hline Decision of the transport provider e.g. flight cancellation & $15(21 \%)$ & $11(22 \%)$ & $4(20 \%)$ \\
\hline Other, please specify & $4(6 \%)$ & $3(6 \%)$ & $1(5 \%)$ \\
\hline \multicolumn{4}{|l|}{ When would the furthermost affected trips? } \\
\hline Up to one week from now & $15(21 \%)$ & $13(25 \%)$ & $2(10 \%)$ \\
\hline Up to one month from now & $27(38 \%)$ & $17(33 \%)$ & $10(50 \%)$ \\
\hline Up to three months from now & $15(21 \%)$ & $13(25 \%)$ & $2(10 \%)$ \\
\hline Up to six months from now & $3(4 \%)$ & $0(0 \%)$ & $3(15 \%)$ \\
\hline Up to one year from now & $2(3 \%)$ & $1(2 \%)$ & $1(5 \%)$ \\
\hline $\mathrm{n} / \mathrm{a}$ & $9(13 \%)$ & $7(14 \%)$ & $2(10 \%)$ \\
\hline
\end{tabular}

Nearly all respondents (93\%) wash their hands regularly as a precautionary measure. Next, a similar proportion $(73 \%-76 \%)$ of the total respondents, avoid unnecessary travelling and social interaction. Also, more than half of them $(66 \%)$ work from home, but a much lower proportion took some medical supplements or vaccinations $(20 \%)$ or wore a facial mask $(17 \%)$. There are some variations across the two groups; a higher proportion of non-Europeans wear facial mask regularly (40\%, compared with $8 \%$ ) and avoid unnecessary travelling (90\%, compared with 67\%). In comparison, a higher proportion of Europeans work from home (76\%, compared with 40\%). Other precautionary measures are avoiding bodily contact and handshake.

Table 5 Precautionary measures

\begin{tabular}{|c|c|c|c|}
\hline & $\begin{array}{c}\text { All } \\
(n=71)\end{array}$ & $\begin{array}{l}\text { Europe } \\
(n=51)\end{array}$ & $\begin{array}{c}\text { Asia, Australia, M East } \\
(n=20)\end{array}$ \\
\hline \multicolumn{4}{|l|}{ Precautionary measures* } \\
\hline I took additional health or travel insurance & $6(8 \%)$ & $4(8 \%)$ & $2(10 \%)$ \\
\hline I spend more on tickets to ensure I can adjust my travel date & $3(4 \%)$ & $1(2 \%)$ & $2(10 \%)$ \\
\hline I wear protective mask everyday & $12(17 \%)$ & $4(8 \%)$ & $8(40 \%)$ \\
\hline I wash my hands regularly & $66(93 \%)$ & $46(90 \%)$ & $20(100 \%)$ \\
\hline I work from home & $47(66 \%)$ & $39(76 \%)$ & $8(40 \%)$ \\
\hline I avoid unnecessary travelling & $52(73 \%)$ & $34(67 \%)$ & $18(90 \%)$ \\
\hline I avoid unnecessary social interaction & $54(76 \%)$ & $40(78 \%)$ & $14(70 \%)$ \\
\hline I took medical supplements and vaccinations & $14(20 \%)$ & $8(16 \%)$ & $6(30 \%)$ \\
\hline
\end{tabular}

We calculate the mean values for the various personal perceptions of teleconferences (Table 6). The participants found the use of telecommunications in comparison to face-to-face meetings somewhat useful (2.06) and are somewhat satisfied with it (2.17). They are also somewhat likely to use it instead of face-to-face meetings post-COVID 19. The non-European respondents are more positive and more likely to use the service instead of face-to-face meetings. The reasons to not use the services are: personal preference, better communication with face-to-face contact, a more direct connection is required, physical pain or annoyance with electronic sounds, expectation from the counterparts, transition time required, activity in person is more meaningful, unpracticality to use technology, delays and interruptions, and hard to keep focus due to lack of real facial expression.

Table 6 Personal perception of the teleconference

\begin{tabular}{|c|c|c|c|}
\hline & $\begin{array}{c}\text { All } \\
\text { mean (SD);n }\end{array}$ & $\begin{array}{c}\text { Europe } \\
\text { mean }(\text { SD);n }\end{array}$ & $\begin{array}{c}\text { Asia, Australia, M East } \\
\text { mean (SD);n }\end{array}$ \\
\hline \multicolumn{4}{|l|}{ Personal perception of the teleconference } \\
\hline $\begin{array}{l}\text { What is the level of usefulness of the telecommunication services } \\
\text { in comparison to a face-to-face meeting? }(1=\text { extremely useful })\end{array}$ & $2.06(0.86) ; 65$ & $2.12(0.93) ; 49$ & $1.88(0.62) ; 16$ \\
\hline $\begin{array}{l}\text { What is the level of satisfaction in the telecommunication service } \\
\text { in comparison to a face-to-face meeting? }(1=\text { extremely satisfy })\end{array}$ & $2.17(0.78) ; 65$ & $2.22(0.74) ; 49$ & $2(0.89) ; 16$ \\
\hline $\begin{array}{l}\text { How likely will you use these tools instead of traveling } \\
\text { long-distance post COVID-19? }(1=\text { extremely likely })\end{array}$ & $2.37(1.1) ; 71$ & $2.47(1.12) ; 51$ & $2.1(1.02) ; 20$ \\
\hline
\end{tabular}

Note: we omitted participants who selected unknown from mean calculation

We calculated the mean ranking and Kendall's coefficient of concordance (w) for three questions (Table 7). The top-three most concerns by the respondents are impacts on their family and relatives, their health, and financial loss. There is a low level of consensus among the respondents $(\mathrm{w}=0.33)$. There are also group differences: 
non-Europeans value inconvenience above financial loss and social stigma above loss of time. The level of consensus is even higher among the Europeans. Other additional concerns are work-related responsibilities, the uncertainty of the health system capacity, unforeseen further complications, death, lack of social interaction and exercise, the transmission of disease to others, broader societal impacts, and loss of opportunity.

Regarding reasons to alter trips, the top-three rationales are taking precautionary action, avoiding the possible inconvenience, and avoiding the potential additional cost. The level of consensus is low (0.26). There are group differences: non-European group ranks avoiding possible delay higher than avoiding potential additional cost. The group also has a higher level of consensus on this topic.

The top-three sources of information the respondents based their decision on are: official announcement, press, and their opinions. The level of consensus on this topic is the lowest among the three topics. The non-Europeans rank news and the opinion of friends and family higher than the Europeans. The levels of consensus among the two groups on this topic are similar.

Table 7 Ranking and concordance

\begin{tabular}{|c|c|c|c|}
\hline & $\begin{array}{c}\text { All } \\
\mathrm{n}=71\end{array}$ & $\begin{array}{c}\text { Europe } \\
\mathrm{n}=51\end{array}$ & $\begin{array}{l}\text { Asia, Australia, M East } \\
n=20\end{array}$ \\
\hline \multicolumn{4}{|c|}{ Rank three most concerning impacts should you be infected with COVID-19? } \\
\hline Personal health & 2 & 2 & 2 \\
\hline Health of family and relative & 1 & 1 & 1 \\
\hline Financial loss & 3 & 3 & 4 \\
\hline Inconvenience & 4 & 5 & 3 \\
\hline Loss of time & 5 & 4 & 6 \\
\hline Social stigma & 6 & 6 & 5 \\
\hline & $\mathrm{w}=0.33$ & $\mathrm{w}=0.35$ & $\mathrm{w}=0.30$ \\
\hline \multicolumn{4}{|c|}{ Rank three of your most important reasons to cancel, postpone or pending these trips? } \\
\hline $\begin{array}{l}\text { Taking a precautionary measure not to get } \\
\text { infected }\end{array}$ & 1 & 1 & 1 \\
\hline Avoid possible delay & 4 & 4 & 3 \\
\hline Avoid possible inconvenience & 2 & 2 & 2 \\
\hline Avoid possible additional cost & 3 & 3 & 4 \\
\hline Other, please specify & 5 & 5 & 5 \\
\hline & $\mathrm{w}=0.26$ & $\mathrm{w}=0.23$ & $\mathrm{w}=0.35$ \\
\hline \multicolumn{4}{|c|}{ Rank three most influential sources of information to you base your decision on } \\
\hline Government and official announcement & 1 & 1 & 2 \\
\hline Press and news agency & 2 & 2 & 1 \\
\hline Unofficial news on social media & 5 & 5 & 5 \\
\hline Opinion of friends/family & 4 & 4 & 3 \\
\hline Personal opinion & 3 & 3 & 4 \\
\hline Others, please specify & $\begin{array}{c}6 \\
\mathrm{w}=0.20\end{array}$ & $\begin{array}{c}6 \\
w=0.22\end{array}$ & $\begin{array}{c}6 \\
w=0.20\end{array}$ \\
\hline
\end{tabular}

\section{B. Additional analysis}

In this section, we present the results of analyses that examine the relationships between selected sociodemographic attributes, perceived risk factors, and trip-related decisions. We do not include here the results of statistical analysis, such as t-test, logistic regression, and multi variance analysis, as our study is still in the preliminary stage with a limited sample size.

Table 8 below shows the comparison, on average, of the score of perceived factors by respondents who altered or did not alter their three types of trips (commuting, non-commuting domestic, and non-commuting overseas trips). We also calculated perceived risk by multiplying likelihood and impact perceived and adjusted the factor by the square root (Sadique et al., 2007).

For the commuting trips, the respondents who altered their trips rated COVID-19 as more dangerous with a higher rate of likelihood to be infected during a long trip and less certain on the information than the other group. However, those who did not alter their commuting trip rate COVID-19 as having a more direct impact on them. For non-commuting domestic trips, the opposite patterns are observed; those who altered these trips rated COVID-19 as a less dangerous and a lower rate of likelihood to be infected than those who did not alter their trips. The information certainty rates of these two groups are approximately the same. For the non-commuting overseas trips, a similar pattern to the commuting trips is shown; those who altered these trips rate COVID-19 as more dangerous with a higher likelihood for infection. In addition, they also rate the directness of impacts as more direct.

The finding suggests that perceived factors considered may have some influence on how the respondents altered, postponed or cancelled their trips. Also, it suggests there may be a difference between how the respondents consider these three types of trips. However, further investigation will be required to draw any conclusive outcomes as the current sample size is too limited for any statistical analysis. Additionally, there may be external factors that overrule personal trip-related decision (e.g. cancellation of events by organizers). 
Table 8 Perceived factors and trips

\begin{tabular}{|c|c|c|c|c|c|c|c|}
\hline & \multicolumn{2}{|c|}{ Commuting trip } & \multicolumn{2}{|c|}{ Non-commuting Domestic trip } & \multicolumn{2}{|c|}{ Non-commuting Overseas trip } & \multirow{2}{*}{$\begin{array}{c}\text { All } \\
n=71\end{array}$} \\
\hline & Altered & Not altered & Altered & Not altered & Altered & Not altered & \\
\hline $\begin{array}{l}\text { Danger } \\
\text { ( } 1=\text { extremely dangerous })\end{array}$ & $2.16(1.18) ; 43$ & $2.37(1.07) ; 19$ & $2.27(1.17) ; 49$ & $2.08(1.04) ; 13$ & $2.04(0.99) ; 48$ & $2.86(1.41) ; 14$ & $2.23(1.14)$ \\
\hline $\begin{array}{l}\text { Directness } \\
(1=\text { extremely direct })\end{array}$ & $2.26(1.14) ; 46$ & $2.19(1.12) ; 21$ & $2.23(1.14) ; 53$ & $2.29(1.14) ; 14$ & $2.12(1.05) ; 49$ & $2.56(1.29) ; 19$ & $2.24(1.13)$ \\
\hline $\begin{array}{l}\text { Infection likelihood } \\
\text { (1 = extremely likely) }\end{array}$ & $2.09(0.75) ; 47$ & $2.48(0.93) ; 21$ & $2.24(0.82) ; 54$ & $2.07(0.83) ; 14$ & $2.17(0.81) ; 52$ & $2.31(0.87) ; 16$ & $2.21(0.82)$ \\
\hline $\begin{array}{l}\text { Information certainty } \\
(1=\text { extremely certain })\end{array}$ & $2.31(1.04) ; 49$ & $2.15(0.88) ; 20$ & $2.27(1.04) ; 55$ & $2.21(0.80) ; 14$ & $2.27(1.12) ; 52$ & $2.24(0.44) ; 17$ & $2.26(0.99)$ \\
\hline Danger x likelihood (adj) & $2.07(0.78) ; 43$ & $2.16(0.61) ; 19$ & $2.10(0.75) ; 49$ & $2.08(0.70) ; 13$ & $1.99(0.73) ; 48$ & $2.45(0.63) ; 14$ & $2.1(0.73)$ \\
\hline
\end{tabular}

Note: Mean score (SD); sample no.

We attempted to delineate the effects of external factors by compared perceived factors of respondents who altered their trips solely on the personal decision with others (i.e. those that based their decision only on external factors, such as event organisers, government, and transport providers or on both personal and external factors) and all respondents. The table below shows the comparison. Contrary to our expectations, those who altered their trip solely based on their opinion rated COVID-19 as less dangerous than the other group. However, they rated the directness of impact and the likelihood to be infected higher and were more confident on the information they have.

Table 9 Perceived factors of COVID-19 and personal decision

\begin{tabular}{lccc}
\hline Perceived factors of COVID-19 & $\begin{array}{c}\text { Altered trips based on } \\
\text { personal opinion only }\end{array}$ & $\begin{array}{c}\text { Altered trips NOT based } \\
\text { solely on personal opinion }\end{array}$ & $\begin{array}{c}\text { All } \\
\mathbf{n = 7 1}\end{array}$ \\
\hline $\begin{array}{l}\text { Danger } \\
(1=\text { extremely dangerous) }\end{array}$ & $2.38(1.45) ; 13$ & $2.18(1.05) ; 49$ & $2.23(1.14)$ \\
$\begin{array}{l}\text { Directness } \\
(1=\text { extremely direct) }\end{array}$ & $2.08(0.96) ; 13$ & $2.28(1.17) ; 54$ & $2.24(1.13)$ \\
$\begin{array}{l}\text { Infection likelihood } \\
(1=\text { extremely likely) }\end{array}$ & $2.08(0.76) ; 13$ & $2.24(0.84) ; 55$ & $2.21(0.82)$ \\
$\begin{array}{l}\text { Information certainty } \\
(1=\text { extremely certain) }\end{array}$ & $2.08(0.64) ; 13$ & $2.30(1.06) ; 56$ & $2.26(0.99)$ \\
Danger x likelihood (adj) & $2.11(0.77) ; 13$ & $2.09(0.73) ; 49$ & $2.1(0.73)$ \\
\hline
\end{tabular}

Note: Mean score (SD); sample no.

Next, we examined how the perceived factors may vary across different sociodemographic groups of respondents. We selected three categories; country of residence (Table 10), sex, and prior experience with significant disruption (Table 11). On average, the respondents perceived COVID-19 to be somewhat dangerous (2.23) and to have a somewhat direct impact (2.24). They also believe they are somewhat likely to be infected during long-distance travelling (2.21) and are somewhat certain on the information they have about the virus (2.26).

At the regional level, it appears that the non-Europeans are less optimistic, concerning the danger, impact, and likelihood to be infected. They also seem to be more confident in the information received. The non-European respondents appear to have a higher level of perceived risk (1.84, compared to 2.2). At the country level, there are also interesting variations; Italian respondents gave the highest danger rating, while the Japanese respondents rated the directness of COVID-19's impact the highest and are relatively more certain on the information. However, while the Dutch respondents are relatively more optimistic about its danger and directness than other groups, they gave a higher rating on infection likelihood than others.

Table 10 Perceived factors and country of residence

\begin{tabular}{|c|c|c|c|c|c|c|}
\hline \multirow{2}{*}{$\begin{array}{l}\text { Perceived factors of } \\
\text { COVID-19 }\end{array}$} & \multicolumn{2}{|c|}{ Region } & \multicolumn{3}{|c|}{ Selected country of residence } & \multirow{2}{*}{$\underset{n=71}{\text { All }}$} \\
\hline & $\begin{array}{c}\text { Europe } \\
n=51\end{array}$ & $\begin{array}{c}\text { Asia, Australia, } \\
\text { M East } \\
n=20\end{array}$ & $\begin{array}{c}\text { Netherlands } \\
n=18\end{array}$ & $\begin{array}{l}\text { Italy } \\
n=15\end{array}$ & $\begin{array}{c}\text { Japan } \\
n=9\end{array}$ & \\
\hline $\begin{array}{l}\text { Danger } \\
\text { (1= extremely dangerous) }\end{array}$ & $2.3(1.17)$ & $2.23(1.14)$ & $2.38(1.12)$ & $1.93(1.21)$ & $2.38(1.51)$ & $2.23(1.14)$ \\
\hline $\begin{array}{l}\text { Directness } \\
(1=\text { extremely direct })\end{array}$ & $2.31(1.24)$ & $2.27(1.14)$ & $2.71(1.26)$ & $2.33(1.35)$ & $2.00(1.00)$ & $2.24(1.13)$ \\
\hline $\begin{array}{l}\text { Infection likelihood } \\
\text { (1 = extremely likely) }\end{array}$ & $2.22(0.79)$ & $2.14(0.75)$ & $2.22(0.65)$ & $2.4(0.91)$ & $2.38(1.06)$ & $2.21(0.82)$ \\
\hline $\begin{array}{l}\text { Information certainty } \\
(1=\text { extremely certain })\end{array}$ & $2.41(1.02)$ & $2.25(1.04)$ & $2.78(1.22)$ & $2.29(0.83)$ & $2.11(0.6)$ & $2.26(0.99)$ \\
\hline Danger x likelihood (adj) & $2.2(0.75)$ & $2.08(0.76)$ & $2.38(0.79)$ & $1.98(0.64)$ & $2.13(0.73)$ & $2.1(0.73)$ \\
\hline
\end{tabular}

Note: Mean score (SD)

The female respondents rated the perceived danger of COVID-19 higher, less direct, and a higher likelihood to be infected than their male counterparts. The certainty of information between the two groups is similar. Individuals with prior experience on similar disruption perceived a similar level of danger than 
other groups but rate its impact as more direct, believed they were less likely to be infected but were less certain about the given information.

Table 11 Perceived factors and selected sociodemographic information

\begin{tabular}{lccccc}
\hline $\begin{array}{l}\text { Perceived factors of } \\
\text { COVID-19 }\end{array}$ & \multicolumn{2}{c}{$\begin{array}{c}\text { Sex } \\
\text { Male }\end{array}$} & $\begin{array}{c}\text { Female } \\
\mathrm{n}=28\end{array}$ & $\mathrm{n}=43$ & \multicolumn{2}{c}{$\begin{array}{c}\text { Prior experience with large } \\
\text { scale disruption } \\
\text { Yes }\end{array}$} & $\begin{array}{c}\text { No } \\
\mathrm{n}=62\end{array}$ & $\mathrm{n}=71$ \\
\hline $\begin{array}{l}\text { Danger } \\
(1=\text { extremely dangerous) }\end{array}$ & $2.31(1.19)$ & $2.17(1.11)$ & $2.22(1.2)$ & $2.23(1.14)$ & $2.23(1.14)$ \\
$\begin{array}{l}\text { Directness } \\
(1=\text { extremely direct) }\end{array}$ & $2.12(1.18)$ & $2.32(1.11)$ & $2.00(1.07)$ & $2.27(1.14)$ & $2.24(1.13)$ \\
$\begin{array}{l}\text { Infection likelihood } \\
(1=\text { extremely likely) }\end{array}$ & $2.54(0.84)$ & $1.98(0.73)$ & $2.67(1.12)$ & $2.14(0.75)$ & $2.21(0.82)$ \\
$\begin{array}{l}\text { Information certainty } \\
(1=\text { extremely certain) }\end{array}$ & $2.26(0.98)$ & $2.26(1.01)$ & $2.33(0.71)$ & $2.25(1.04)$ & $2.26(0.99)$ \\
Danger x likelihood (adj) & $2.19(0.81)$ & $2.03(0.67)$ & $2.19(0.59)$ & $2.08(0.76)$ & $2.1(0.73)$ \\
\hline Note: Mean score (SD) & & & & &
\end{tabular}

\section{REFLECTIONS AND DISCUSSION}

This exploratory study provides an early reporting into how COVID-19 may affect travelling and some insights into the underlying reasons behind how our respondents altered their trips in the face of the pandemic. There are several limitations of the study, resulting from the methodology and the concise duration of the survey. For instance, the internet-based platform and the language of the survey limited broader participants from taking part. The sample size is small and has inherent biases that restricted statistical analysis of the data and wide-scale generalization of the results. Additionally, there are also some possible improvements to our questionnaire and the presumption we made; for instance, we assumed that the respondents had at least one planned overseas trip. Moreover, the survey is a brief snapshot of highly dynamic and complex impacts resulting from COVID-19 outbreaks that are still on-going with a unique circumstance in each country. The findings of the survey can be summarized and compared with previous studies in the following paragraphs.

At the time of the survey, only $30 \%$ of the respondents were commuting as usual; $39 \%$ of them worked and studied from home every day, $27 \%$ worked from home some days, and $15 \%$ shifted their commuting time. A higher percentage of European respondents were working from home, while others shifted their commuting time (Table 2-3). These results are in line with Google's community report, which depicted a drop of work trips between 7\% (Japan) to 63\% (Italy) relatively to the pre-COVID19 baseline. The regional differences may stem from a more flexible working culture in Europe that enables individuals to work from home or more stringent measures to limit social interaction in European countries at the time of the survey.

Our survey also shows $21-25 \%$ of the respondents did not cancel or postpone their non-commuting domestic and overseas trips. However, these are likely to be an overestimate; our respondents completed the surveys before President Trump prohibited all non-essential arrivals from the EU to the US on March 15. Additionally, the EU also prohibited all visitors from outside the Schengen free-travel zone to enter on March 16.

The top three reasons behind the alterations of non-commuting trips (Table 4) are the decision of the organizers (45\%), personal opinion (45\%), and the decision of the government (35\%). Our analysis also shows that up to $18 \%$ or one in five of the respondents decided solely by their opinion, which in turn can be influenced by the way they perceived risk.

Additionally, the respondents ranked health of family and relative as a more concerning issue than own health (Table 7). They adjusted their travel to avoid getting infected and any possible delay and relied on official announcement and press release for information. The Europeans ranked their personal opinion above family as friends; the opposite was observed in the non-European group. These findings emphasize how improvements to the way we understand and communicate risks of infectious disease can complement other measures, such as social distancing and physical lock-down, to prevent the public from unnecessary exposure to the pandemics.

The respondents thought teleconference is a somewhat useful tool and were satisfied with it. They were likely to continue using the tool instead of long-distance travel (Table 6). In this study, we examine teleconference as technology in isolation. Instead, it can be beneficial to investigate the decision behind how teleconference is utilized as a substitute for a face-to-face meeting, as a precautionary measure, and in combination with the flexible working condition that facilitates working from home.

Some correlations between the perceived factors and how the respondents altered their trips can be observed (Table 8). However, the relationships are different across the three types of trips considered. The finding suggests the respondents may consider these trips differently. For instance, they may consider regular commuting and 
long-overseas trips in a similar way, whereas shorter domestic trips are considered differently. Future studies may investigate these differences further.

Sociodemographic attributes seem to affect perceived factors. For instance, the European respondents were more optimistic and had a lower level of perceived danger and likelihood to be infected. However, it is uncertain how homogenous these clusters are. Future studies with a larger sample size can help to elucidate these differences better.

Additionally, certain observations, such as how those who based their trip decision solely on their personal opinion perceived COVID-19 as less dangerous than others, are counter-intuitive. These surprising observations can be omitted as outliers but may suggest how risk perception may be more complex and dynamic. For instance, those who perceived a higher level of risk may take precautionary actions, such as vaccination, which in turn reduce their risk perception (See, e.g. Brewer et al., 2004). We will consider how to incorporate these dynamics in the revised model.

\section{NEXT STEPS}

We look to examine further the relationship between the perceived factors and their effects on trip decisions and would be grateful to receive comments and critique on our approach. Additionally, please do not hesitate to get in touch, should be interested to learn more about this study or are interested in a potential collaboration.

\section{ACKNOWLEDGEMENT}

We thank Radboud University, particularly Prof. Etiënne Rouwette and Assoc. Prof. Hubert Korzilius for providing the survey platform access for this research. We also thank Robert Binder, Future Earth Japan colleagues; Giles Sioen and Yuki Hashimoto, Asst. Prof. Saroch Boonsiripant, and Yale Wong for their feedbacks and comments.

\section{REFERENCES:}

BBC. (2020). Coronavirus: A visual guide to the world in lockdown - BBC News. Retrieved April 9, 2020, from https://www.bbc.com/news/world-52103747

Brewer, N. T., Weinstein, N. D., Cuite, C. L., \& Herrington, J. E. (2004). Risk Perceptions and Their Relation to Risk Behavior. Annals of Behavioral Medicine, 27(2), 125-130. https://doi.org/10.1207/s15324796abm2702_7

Business Insider. (2020). Countries that are on lockdown because of coronavirus - Business Insider. Retrieved April 1, 2020, from Businessinsider.com website: https://www.businessinsider.com/countries-on-lockdown-coronavirus-italy-2020-3

GWI. (2020). Coronavirus Research | March 2020 Series 2: Travel \& Commuting. Retrieved from https://www.globalwebindex.com/hubfs/1. Coronavirus research assets/GWI coronavirus findings March 2020 - Travel (Release 2).pdf

Pavli, A., Tsiodras, S., \& Maltezou, H. C. (2014). Middle East respiratory syndrome coronavirus (MERS-CoV): Prevention in travelers. Travel Medicine and Infectious Disease, 12(6), 602-608. https://doi.org/10.1016/j.tmaid.2014.10.006

Peeri, N., Bibi, S., \& Baghbanzadeh, M. (2020). The SARS, MERS and novel coronavirus (COVID-19) epidemics, the newest and biggest global health threats: what lessons have we learned? International Journal Of Epidemiology, (February). https://doi.org/10.1093/ije/dyaa033

Sadique, M. Z., Edmunds, W. J., Smith, R. D., Meerding, W. J., De Zwart, O., Brug, J., \& Beutels, P. (2007). Precautionary behavior in response to perceived threat of pandemic influenza. Emerging Infectious Diseases, 13(9), 1307-1313. https://doi.org/10.3201/eid1309.070372

WHO. (2020). Coronavirus disease 2019. Retrieved April 1, 2020, from WHO website: https://www.who.int/emergencies/diseases/novel-coronavirus-2019

Wilder-Smith, A. (2006). The severe acute respiratory syndrome: Impact on travel and tourism. Travel Medicine and Infectious Disease, 4(2), 53-60. https://doi.org/10.1016/j.tmaid.2005.04.004 
Working paper: An exploratory survey on the perceived risk of COVID-19 and travelling

\section{APPENDIX}

Worldwide lockdown timeline

Source: (BBC, 2020)

\section{Asia, Australia and New Zealand in lockdown}

Dates and severity of restricted internal movement by country

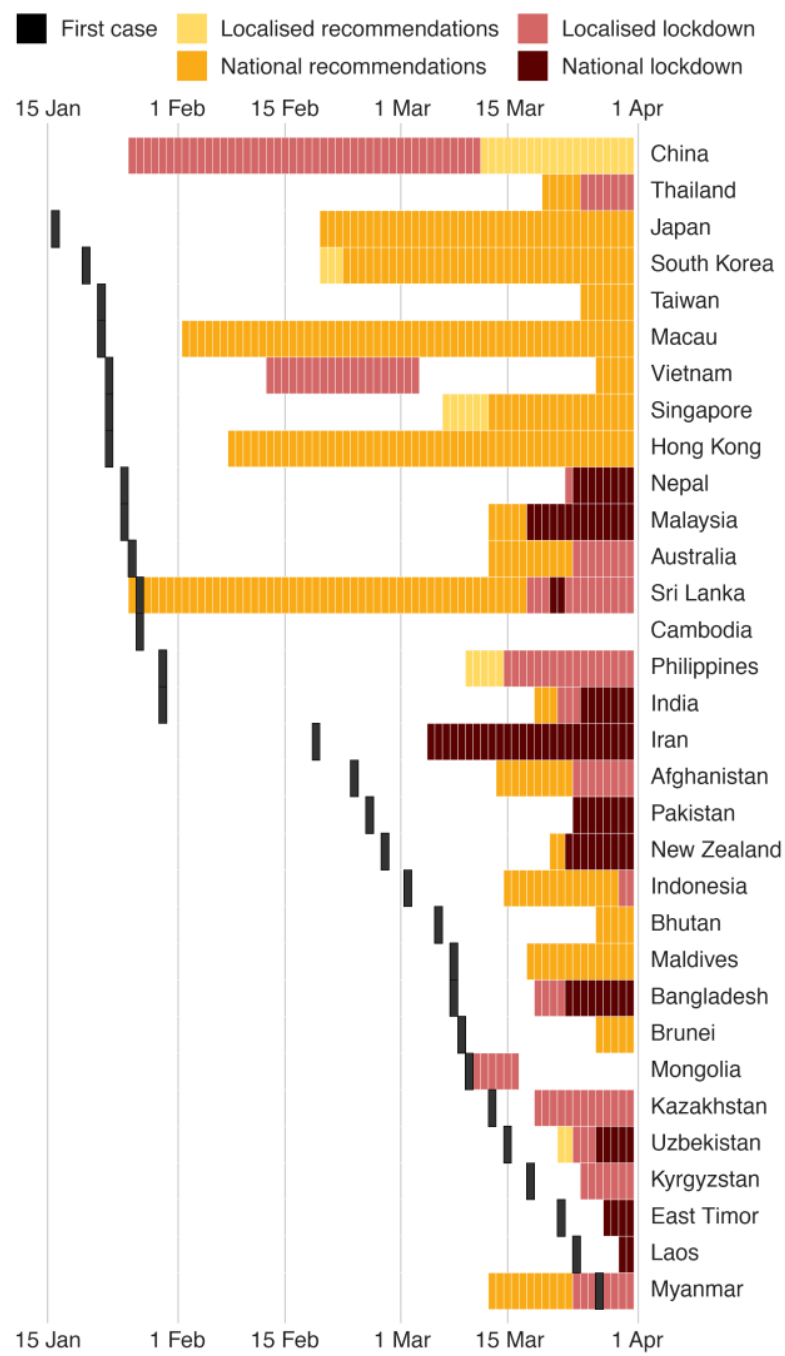

\section{European countries in lockdown}

Dates and severity of restricted internal movement by country

- First case Localised recommendations 2 Localised lockdown

15 Jan 1 Feb 15 Feb 1 Mar 15 Mar 1 Apr

| 1 |

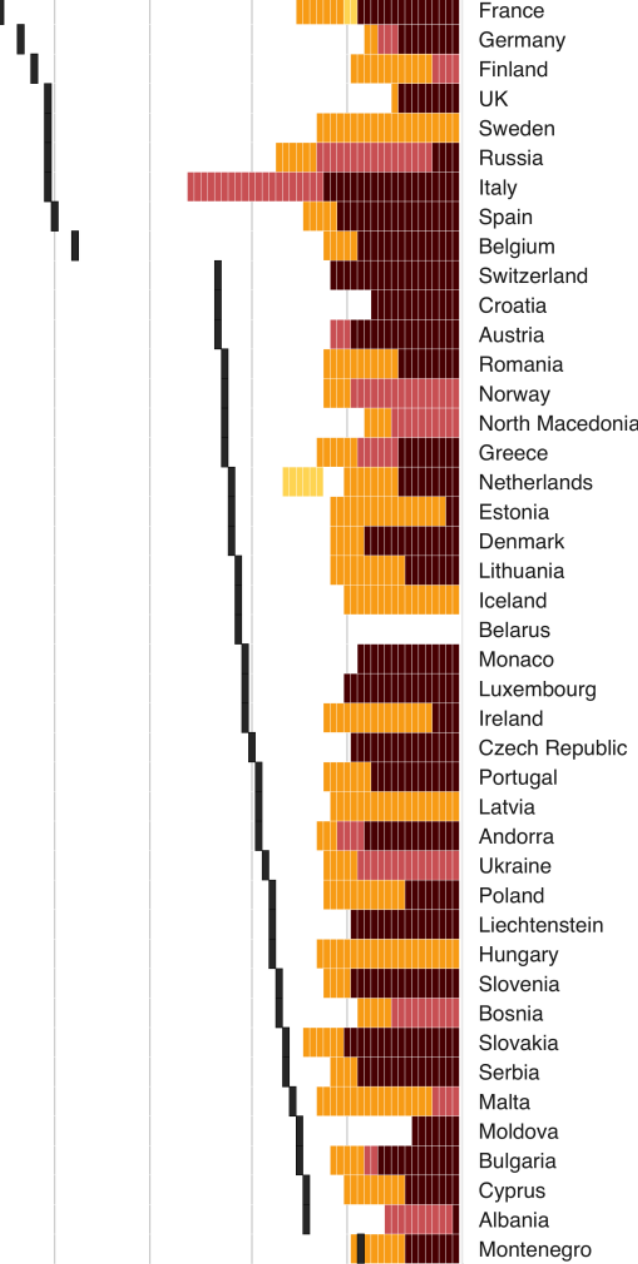

Note: China and Thailand confirmed their first cases prior to 15 January 2020

15 Jan 1 Feb 15 Feb 1 Mar 15 Mar 1 Apr

BBC 
Working paper: An exploratory survey on the perceived risk of COVID-19 and travelling

\section{Countries in the Americas in lockdown}

Dates and severity of restricted internal movement by country

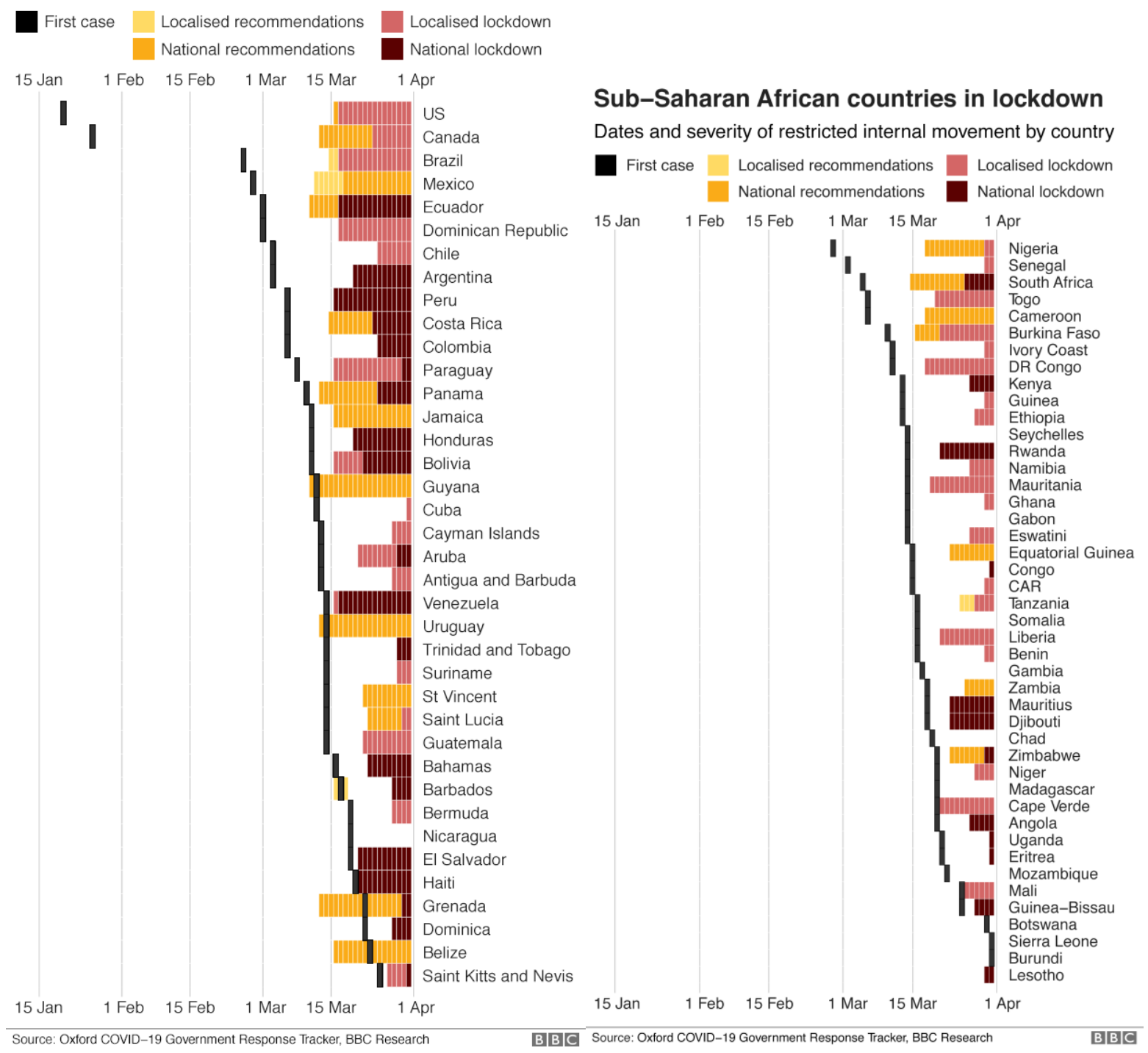

